\title{
O corpo como metaobjeto na escrita coletiva de um manifesto político sobre design
}

\author{
The body as a metaobject in the collective writing of a political manifesto on design
}

\author{
Rafaela Angelon, Frederick Marinus Constant van Amstel
}

corpo, metadesign, manifesto político, design social

O corpo humano na literatura de codesign é geralmente referido como uma fonte ou recurso para o design corporificado mas não na expressão política e ontológica. Essa redução do corpo dificulta a inclusão nas abordagens de design de questões políticas que surgem da existência social desse corpo, tais como sexismo, racismo e outras formas de opressão. Esta pesquisa apresenta uma análise de ações corporificadas realizadas por estudantes de design em um projeto de manifesto coletivo sobre o papel do designer na manutenção e distribuição de privilégios na sociedade. A análise interacional apresentou evidências de que, nessa situação em particular, o corpo desempenhou o papel de meio para articular criticamente o dissenso entre os estudantes além de representar o próprio dissenso pela existência corporificada do ser em dissenso. Podemos concluir com a análise deste caso que o corpo, além de ser recurso ou fonte de informação, pode também atuar também como um metaobjeto efetivo em projetos de codesign.

body, metadesign, political manifesto, social design

The human body in codesign literature is often referred to as a source or resource for embodied design but not in political and ontological expression. This reduction of the body makes it difficult for design approaches to include political issues that arise from the social existence of that body, such as sexism, racism and other forms of oppression. This research presents an analysis of embodied actions performed by design students in a collective manifesto project on the designer's role in the maintenance and distribution of privileges in society. The interactional analysis presented evidence that, in this particular situation, the body played the role of a means to critically articulate the dissent among students, besides representing the dissent itself by the embodied existence of the dissenting being. We can conclude with the analysis of this case that the body, in addition to being a resource or source of information, can also act as an effective metaobject in codesign projects.

\section{Introdução}

Designers são responsáveis por impactar indiretamente os entornos da cultura através do espaço moldado por seus projetos. A consciência crítica no desenvolvimento de projetos se torna necessária para enfrentar o desafio ético de projetar, pois sua implementação ressoa em vários aspectos corporais da vida cotidiana (HÖÖK, 2018). Dada a dimensão deste impacto, os aspectos políticos relativos ao design não podem ser tomados de forma simplista, correndo o

Anais do $10^{\circ} \mathrm{CIDI}$ e $10^{\circ} \mathrm{CONGIC}$

Kelli C.A.S. Smythe, Rafael de Castro Andrade (orgs.)

Sociedade Brasileira de Design da Informação - SBDI

Curitiba | Brasil | 2021
Proceedings of the $10^{\text {th }} \mathrm{CIDI}$ and $10^{\text {th }}$ CONGIC

Kelli C.A.S. Smythe, Rafael de Castro Andrade (orgs.)

Sociedade Brasileira de Design da Informação - SBDI Curitiba | Brazil | 2021 
risco de reproduzir mecanismos de dominação nas relações sociais mediadas pelo design (NOGUEIRA, PORTINARI, 2016).

A mediação de relações sociais em nossa sociedade é frequentemente realizada por objetos potencialmente opressivos, tais como dispositivos eletrônicos, carros e móveis projetados a partir de uma perspectiva isolada de seus contextos de uso, o que não favorece perceber estruturas sociais invisíveis que operam no reforço das opressões de corpos específicos (HÖÖK, 2018): o corpo da mulher, do negro, do indígena, da pessoa com deficiência e outros corpos oprimidos. Designers são responsáveis por projetar tecnologias que moldam os movimentos, os comportamentos e as mediações das vivências espaciais destes corpos humanos. Porém, a maior parte dos designers não está consciente deste aspecto político do seu trabalho.

Para mudar este cenário, é necessária a compreensão e a consciência crítica do corpo político que a prática de design projeta para e a partir de (ANGELON, VAN AMSTEL, 2020), tanto no processo de aprendizagem quanto na práxis de design. Apesar de existirem pesquisas que abordem o tema, faz-se necessário salientar as práticas pedagógicas e projetuais que protagonizam o corpo político nas escolhas e decisões realizadas em projetos de design.

Com o objetivo de explorar as potencialidades do corpo político no processo de aprendizagem típico da educação em design, esta pesquisa apresenta os resultados de um experimento realizado com estudantes de design. $\mathrm{Na}$ ocasião, os estudantes de design discutiram coletivamente a idealização de um manifesto político sobre o papel do design na manutenção e distribuição de privilégios na sociedade. A escrita deste manifesto foi desenvolvida como parte da disciplina "Projeto para Pessoas: Laboratório de Design e Inovação Social" do Bacharelado em Design da UTFPR. Este curso visava desenvolver habilidades e visões políticas para articular, facilitar, antecipar e organizar projetos de design social. Os registros audiovisuais do experimento foram analisados através da análise interacional (BUR ET AL, 2013) cujo método e resultados serão apresentados a seguir..Esta pesquisa é resultado do plano de trabalho intitulado "Poéticas Corporais no Projeto de Interações e Experiências", vinculado ao projeto "Design de Metaobjetos para Colaboração, Participação e Debate" registrado no Programa Institucional de Voluntariado em Iniciação Científica (PIVIC) da UTFPR.

\section{Material}

O experimento foi estruturado a partir do emprego de metaobjetos na atividade prática, criativa e colaborativa dos estudantes. Metaobjetos podem ser explicados como a "segunda sentença" de afirmações de primeira ordem, ou seja, trata-se de uma materialização simbólica para elucidar algum sentido a ser discutido em um projeto (MANGIERI, 2015). Tratam-se de instrumentos reflexivos gerados para uma finalidade de estudo de um objeto existente que se deseja transformar ou para a projeção de um objeto que se deseja criar. Metaobjetos podem ser tangíveis ou intangíveis, de consistências variáveis, gerados a partir de séries ou conjuntos 
de objetos já existentes mesmo que sua intenção seja explorar novos significados e assim justificar e consolidar ideias complexas (MANGIERI, 2015).

A característica meta de tais objetos refere-se às articulações intersubjetivas que o mesmo capacita na comunicação entre corpos, bem como na inter objetificação do processo criativo. $O$ metaobjeto pode ser material ou virtual, analógico ou digital. Sua característica principal está na intenção de proporcionar um salto criativo para fora da lógica e racionalidade ocidental, marcada por códigos e sistemas de linguagem que legitimam e enrijecem pensamentos (MANGIERI, 2015). O metaobjeto promove friç̧ões entre a realidade atual e suas várias possibilidades de transformação, atuando desta maneira como um mediador de deliberações políticas sobre as realidades que valem a pena dedicar esforços. O metaobjeto participa do processo de politização de seus criadores, mas também se aproveita da consciência política existente.

No experimento estudado, os estudantes deliberavam sobre a atuação de designers na sociedade e percebiam que havia necessidade de maior politização da profissão. Entretanto, cada estudante tinha uma visão política diferente sobre a profissão. O metaobjeto criado neste experimento tinha o objetivo de materializar essas visões políticas por meio do próprio corpo. Os materiais usados para construir o metaobjeto foram tecidos, alfinetes e canetas diversas. A materialização das visões políticas deixou patente a falta de pontos em comum entre os participantes, evidência que acabou se transformando em conteúdo do próprio objeto representado pelo metaobjeto.

\section{Métodos}

Os metaobjetos foram introduzidos no processo pedagógico da disciplina como um experimento de design democrático (BINDER ET AL, 2015), que consistiu em uma tentativa de encontrar formas alternativas para engajar públicos com deliberações democráticas. O objetivo do experimento foi refletir sobre a visão política da profissão para reconhecer os objetivos individuais dos participantes e promover a emergência de objetivos coletivos.

A análise do experimento baseou-se no método de análise interacional (BUR ET AL, 2013), que se vale da análise de registros visuais e escritos do experimento prático. A partir das análises coletadas foi possivel discutir e elucidar conceitos para compreender as relações práticas fundamentadas no corpo. Por meio da análise de interações entre os participantes, o método buscou tornar visível as abstrações que emergem espontaneamente ou são projetadas explicitamente para estruturar o debate.

No início do experimento, os estudantes se apropriaram da sala de aula com seus corpos em diferentes posições e lugares, em pequenos grupos ou individualmente, sentados ou de pé. Cada um rasgou ou cortou um retalho de tecido para escrever o que gostaria de agregar ao manifesto. Quando todos terminaram essa etapa, os retalhos foram dispostos e exibidos em uma mesa. Depois de familiarizar-se com os pedaços escritos pelos colegas, a seguinte etapa consistiu em aproximar ideias conexas e assim conectá-las com o uso de alfinetes. Até então, a turma estava tímida e atuava dividida em pequenos grupos baseadas em experiências 
compartilhadas previamente no curso. O resultado foi uma espécie de colcha de retalhos. Ao estendê-la, emergiu uma atmosfera coletiva através de conversas e diálogos sobre os temas apresentados por todos (Figura 1).

Figura 1 - A colcha de retalhos. Fonte: produzido pela autora.

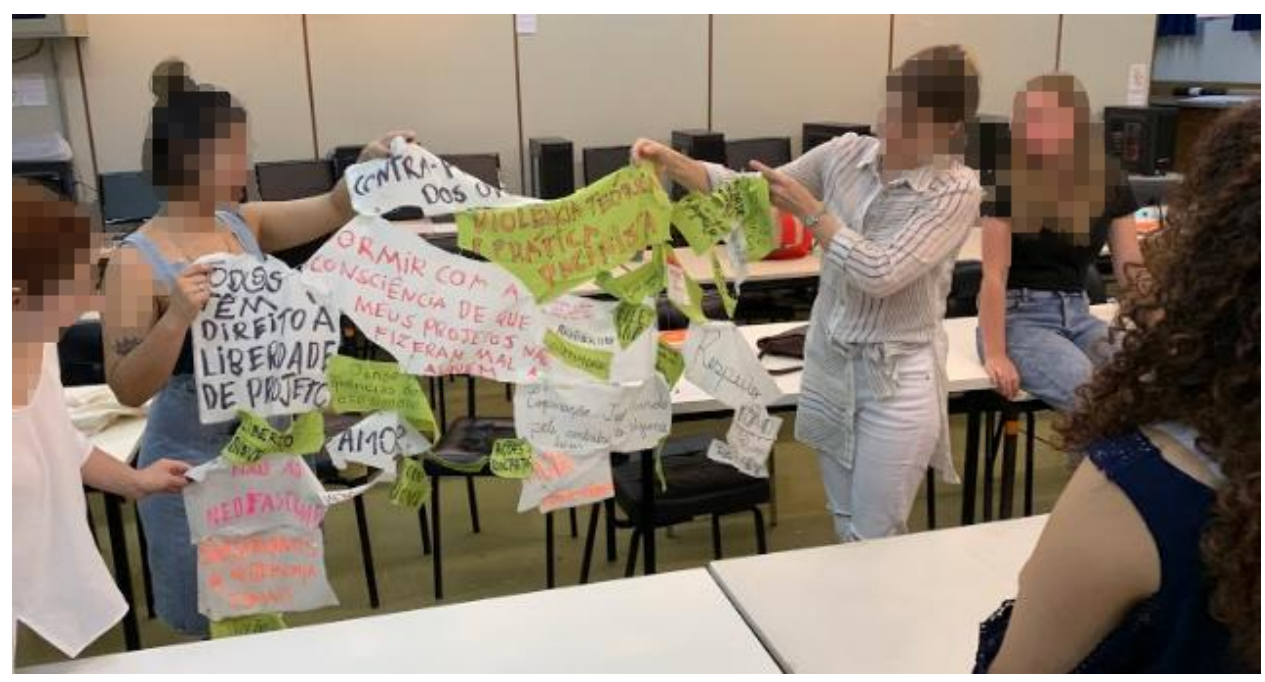

A próxima etapa era a de incorporar a colcha de retalhos que foi, então, vestida como um manifesto por todos os alunos, um de cada vez. Para caber em cada corpo, os colegas ajustavam os alfinetes no corpo do colega. Foi natural a presença de câmeras no ambiente e assim foi natural também a corporificação do manifesto vestível com poses diretamente para a câmera mostrando os diferentes modelos criados individualmente. Cada aluno que vestiu partes do seu corpo com o manifesto vestível vestiu uma forma única e diferente, como um processo de natureza plural e dissensual, reconfigurando portanto a ordem das palavras (Figura 2).

Figura 2 - A reconfiguração do Manifesto Vestível. Fonte: produzido pela autora.

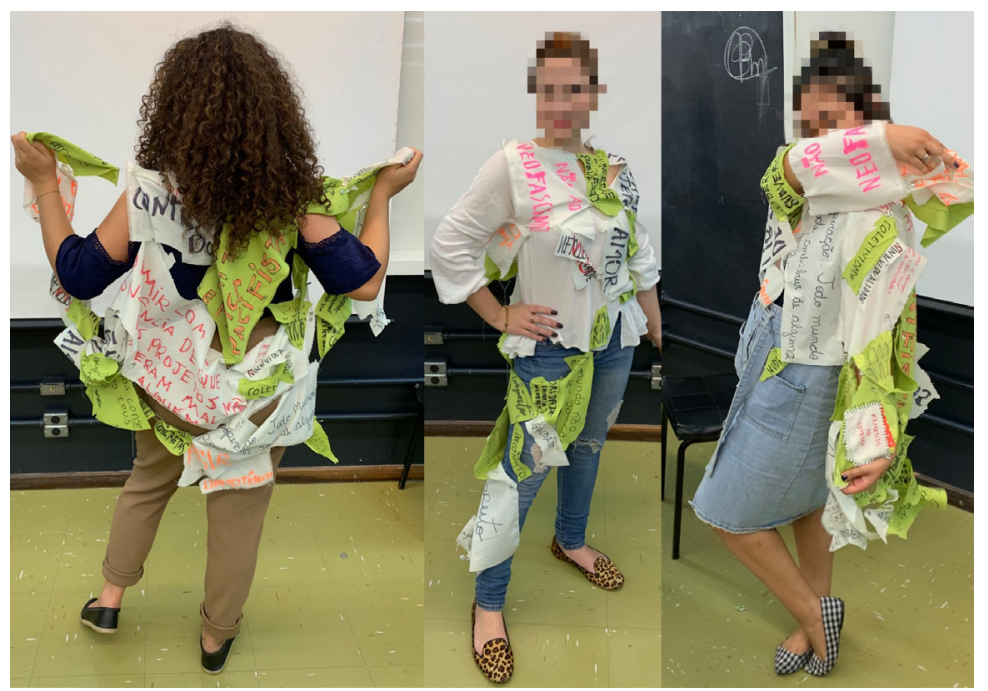


O manifesto vestível permitiu incorporar a pluralidade dos corpos que participaram de sua confecção, bem como das suas visões políticas. O processo de sua montagem coletiva e do vestir individual repercutiu a presença dos corpos no processo prático de desenvolvimento do manifesto coletivo, baseado em uma visão política compartilhada.

\section{Resultados}

Por meio do experimento, foi possível reconhecer um conceito importante: a presença do dissenso como catalisador das diferenças políticas entre os participantes. Ao invés de eliminar essas diferenças através de um consenso forçado, o dissenso foi mantido durante 0 experimento prático no processo de vestir individualmente o manifesto vestível. Devido a isso, o dissenso foi repercutido conceitualmente no título do manifesto, consagrado esteticamente na capa projetada coletivamente (Figura 3).

Figura 3 - Capa do Manifesto Coletivo Escrito. Fonte: Disponibilizado pela turma da disciplina "Projeto para Pessoas".

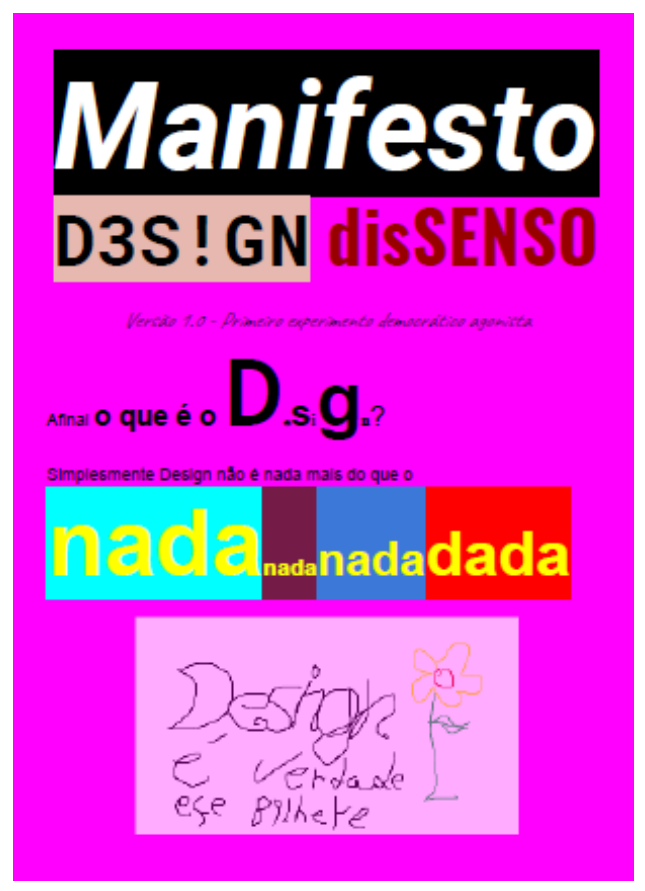

A escrita coletiva do manifesto foi realizada com uma ferramenta de edição de textos colaborativa multiusuário que permitiu que fossem feitas edições simultâneas em vários pontos do manifesto. Os mesmos recursos de edição de texto também foram utilizados para criar uma estética reconhecida como parte do processo coletivo.

\section{Discussões}

Pesquisas anteriores apontaram o dissenso como um meio para a construção de pensamentos críticos não-hegemônicos, capazes de acolher modos de resistência (RISPOLI, 2017). 
A relação entre o design e o dissenso pode ser entendida como uma forma de intervenção política (KESHAVARZ, MAZÉ, 2013). Em uma ordem social específica, o papel do designer, segundo os autores, é o de mediar novos termos e temas de contestação para assim apontar novas trajetórias de ação em meio às diversas perspectivas.

O dissenso apoia não apenas o antagonismo social, o conflito de opinião ou o multiculturalismo no discurso político, mas também sugere a racionalidade da política como um mundo instituído comum e tornado comum por meio da divisão deste mundo através do ato político (RANCIÉRE, 1996). A política antes de ser uma combinação de interesses de grupos, é um recorte da realidade do mundo sensível em oposição a outros recortes da realidade do mesmo mundo sensível (RANCIÉRE, 1996).

Se o dissenso é inerente à qualquer prática democrática, não seria diferente no Design Participativo e Design Social. No experimento descrito acima, o reconhecimento do dissenso quebrou com a hegemonia da atividade profissional de design, dando espaço para possibilidades de consciência política plural que foi expressa tanto no manifesto vestível quanto no manifesto escrito. Esta pesquisa acrescenta à discussão do dissenso no design o viés do corpo político e politizado, que torna-se metaobjeto na mediação de suas próprias singularidades de seu contexto social. O corpo como metaobjeto reproduz recortes de sua realidade expondo tensões que devem ser negociadas entre outros corpos, tal como sugere Ranciére. Neste âmbito, é salientada a importância da presença corporal concreta (em oposição à participação abstrata através de personas e outros dados) dos participantes para representar a pluralidade no projeto de design a partir de seu corpo.

O projeto participativo de um manifesto coletivo tornou-se uma atividade colaborativa mediada por metaobjetos e de práticas democráticas corporificadas. Em meio às diversas perspectivas políticas, o reconhecimento do dissenso quebrou com a hegemonia da atividade profissional de design, dando espaço para possibilidades de consciência política plural que foi expressa tanto no manifesto vestível quanto no manifesto escrito.

\section{Considerações finais}

No experimento, o manifesto vestível vestiu os corpos dos participantes. Essa ação corporificada legitimou-os como metaobjetos de seus próprios ideais, mas também como integrantes do coletivo que emergiu da experiência corporificada. A legitimação do corpo no processo de criação coletiva tornou-se um meio de expressão tanto para expor visões políticas como também para encarnar as ideias políticas do outro e do coletivo.

Além do corpo como metaobjeto, o experimento identificou o dissenso entre os participantes como um resultado da relação entre educação política e as práticas do design. Portanto, o dissenso compôs o espaço para a pluralidade e o desenvolvimento de discussões de perspectivas plurais no projeto design. A educação de futuros designers precisa desenvolver o viés político quanto ao olhar crítico relacionado ao corpo, sobre como nossos corpos são moldados culturalmente e também como tais moldes são reproduzidos pelo design. 
Cabe, portanto, a consideração do corpo nos processos da criação do design para auxiliar uma abordagem corporificada como meio político para a expressão ontológica. Desta maneira, o corpo é visto mais do que como uma concretude, mas como uma unicidade advinda de complexidades e realidades. Essa abordagem do corpo no design pode ser explorada em maior profundidade para pesquisas futuras através de experimentos democráticos corporificados de design.

\section{Agradecimento}

Cabe agradecimento aos participantes do experimento prático realizado na disciplina "Projetos Para Pessoas: Laboratório De Design E Inovação Social" e também à Universidade Tecnológica Federal do Paraná por proporcionar espaço para inovar e estimular novas abordagens políticas acadêmicas.

\section{Referências}

ANGELON, Rafaela; VAN AMSTEL, Frederick M.C. The political body as a fulcrum for radical imagination in metadesign. In: Proceedings of the III Design Culture Symposium, Unisinos, Porto Alegre, Brasil, 2020.

BINDER, T., BRAND, E., EHN, P., \& HALSE, J. Democratic design experiments: between parliament and laboratory. CoDesign, 2015.

BUUR, J., BEUTHEL, M. R., \&amp; CAGLIO, A. Designerly analysis of participation structures. Nordic Design Research Conference, 2013.

HÖÖK, K. Designing with the body - Somaesthetic Interaction Design. The MIT Press, 2018. KESHAVARZ, M., MAZÉ, R. Design and dissensus. Design Philosophy Papers, 2013.

MANGIERI, P. Metaobjetos, Universidad de Los Andes, Venezuela, 2015.

NOGUEIRA, P. C. E., \& PORTINARI, D. B. Por um design político, Estudos em Design, 2016.

RANCIÉRE, J. A crise da razão, Capítulo: O Dissenso. Companhia das Letras, 1996.

RISPOLI, R. Designing dissent. Counter-hegemonic tactics in contemporary design. Journal of Design Processes, 2017.

\section{Sobre os autores}

Rafaela Angelon, aluna, UTFPR, Brasil <angelon@alunos.utfpr.edu.br>

Frederick M. C. van Amstel, Dr., UTFPR, Brasil <usabilidoido@gmail.com> 